\title{
OS DOIS DESTINOS DE
} PORTUGAL:

\section{A PROBLEMÁTICA}

IMAGOLOGIA

PORTUGUESA NO

SEU DIÁLOGO COM A EUROPA*

Contato

Av. Visconde de Jequitinhonha, 2902 - apt. 2202

51 130-020 - Recife - Pernambuco - Brasil bmacedomendonca@hotmail.com

\section{- Bruno Macêdo Mendonça**}

Universidade de Coimbra

Coimbra - Portugal

\section{Resumo}

O artigo parte de representações contidas no romance A jangada de pedra, de José Saramago, lançado no ano do ingresso de Portugal na Comunidade Econômica Europeia, para revisitar o conceito de "imagologia" de Eduardo Lourenço. Tenta-se compreender como episódios traumáticos da história portuguesa deram origem, no passado, a projetos iberistas e à produção de uma autoimagem diminuída de Portugal, em particular no que se refere à sua posição no concerto europeu de nações. Produz-se uma crítica quanto à operacionalidade do conceito de Lourenço, atentando para suas fragilidades intrínsecas, e se adota - também com base na história de Portugal, mas a partir de uma visão mais abrangente postura moderadora, em dissonância com o posicionamento do Prêmio Nobel português. O texto é uma tentativa de estabelecer um diálogo entre História das Ideias e História tout court, no intuito de enriquecer a análise sobre o lugar que ocupa Portugal na Europa.

\section{Palavras-chave}

História - Portugal - Comunidade Econômica Europeia - Imagologia - Iberismo.

* Todas as obras e todos os documentos utilizados na pesquisa e na elaboração do artigo são citados nas notas e na bibliografia.

" Doutorando em Línguas Modernas pelo Departamento de Culturas e Literaturas, Faculdade de Letras da Universidade de Coimbra, Portugal. 


\title{
THE PORTUGUESE
}

IMAGERY ISSUE IN

\section{ITS DIALOGUE WITH}

\section{EUROPE}

Contact

Av. Visconde de Jequitinhonha, 2902 - apt. 2202 $51130-020$ - Recife - Pernambuco - Brazil bmacedomendonca@hotmail.com

\section{- Bruno Macêdo Mendonça**}

Universidade de Coimbra

Coimbra - Portugal

\begin{abstract}
The article stems from representations from José Saramago's novel The stone raft released in the year when Portugal joined the European Economic Community, to revisit Eduardo Lourenço's concept of "imagery". It is an attempt to understand how traumatic episodes of the Portuguese history gave birth, in the past, to Iberian projects and to a diminished Portuguese self-image, especially in relation to Portugal's position amongst the other European countries. A criticism is made as to the functionality of Lourenço's concept, paying attention to its inherent fragilities and having a moderating attitude also based in Portugal's history, but stemming from a broader view, in contrast with the position of the Portuguese Nobel Prize winner. The text tries to establish a dialogue between History of Ideas and History tout court with the purpose of enriching the analysis about Portugal's place in Europe.
\end{abstract}

\section{Keywords}

History - Portugal - European Economic Community - Imagery - Iberism. 
Vejam-se os portugueses, ao longo de suas douradas praias, proa da Europa que foram e deixaram de ser, porque do cais europeu nos depreendemos, mas novamente fendendo as ondas do Atlântico, que almirante nos guia, que porto nos espera. Narrador de A jangada de pedra, de José SARAmago.

Quem te sagrou criou-te português. Do mar e nós em ti nos deu sinal. Cumpriu-se o Mar, e o Império se desfez. Senhor, falta cumprir-se Portugal! Fernando Pessoa

\section{Introdução: os destinos de Portugal}

A revolução de 25 de abril de 1974, que pôs fim ao Estado Salazarista e deu início ao processo de democratização de Portugal, também proporcionou à sociedade portuguesa a oportunidade de discutir diversos temas de natureza política, econômica e social de seu interesse e relacionados ao futuro do país e à definição de seu lugar no concerto das nações, em particular no seu diálogo com uma Europa que desde o fim da Segunda Guerra Mundial trilhava o caminho da integração. O processo de consolidação do bloco europeu que, ao longo do tempo, ultrapassará, em seus objetivos, o atingimento de interesses meramente econômicos, tende a colocar "o lugar de Portugal em xeque" (GODK, 2016, p. 7), exigindo do país respostas rápidas a pressões externas e internas de toda espécie.

Nesse contexto, embora já em 1976 Portugal tenha ingressado no Conselho da Europa e, um ano depois, tenha solicitado formalmente sua adesão à Comunidade Econômica Europeia (CEE), participar da integração não era uma ideia que lograsse obter aprovação unânime de toda a sociedade, muito menos de suas elites intelectuais. Nada mais natural que uma decisão desta envergadura, com as inúmeras e importantes consequências a ela associadas para um Estado secularmente cioso de sua soberania e independência, fosse objeto de debates cujos objetivos eram o de saber se a associação com o continente representaria mais benefícios do que custos para Portugal.

O que chama a atenção, no entanto, não é que se tenham discutido os prós e os contras da aproximação com a Europa, mais precisamente o ingresso na CEE, mas que tal discussão tenha, por vezes, recaído sobre um questionamento subjacente, o de saber se Portugal pertencia a esta entidade enigmática chamada Europa. Pergunta sobremaneira insólita para um pesquisador estrangeiro ao espaço europeu que, ao observar de fora o Velho Continente, ao lembrar-se de sua história e de sua geografia, nunca teve 
dúvidas de que Portugal era Europa, e para quem ouvir falar em Portugal e Europa, enquanto termos dissociados, era a representação mesma de um contrassenso inexplicável.

A leitura de um romance do Prêmio Nobel português, José Saramago, tornou patente que de fato havia um conflito identitário implícito na discussão sobre a integração europeia e que, aparentemente, Portugal, ou ao menos Portugal segundo alguns portugueses, não se sentia inteiramente confortável em abraçar a ideia de Europa. E não porque se questionassem os possíveis resultados pragmáticos desta união, mas sim porque supostamente Portugal não era Europa, não pertencia à Europa. Porque havia ali uma negativa em se associar o país à cultura existente para além dos Pirineus.

A Jangada de pedra, de Saramago, põe, sob o modelo questionador da literatura, esta ideia de cisão identitária em cima da mesa e obriga o analista a revisitar a história para esclarecer e explicitar os fundamentos que estão na origem desta dualidade. Dito de outra forma, o destino dos portugueses seria o Atlântico, com todas as relações e contatos forjados ao longo de sua gloriosa história marítima, ou essa Europa, que agora ressurgia com o rosto de um estranho? "É curioso", diz Eduardo Lourenço (1994, p. 51), expressando com precisão a surpresa que nos leva a escrever este artigo, que "nós, peninsulares, nos refiramos espontaneamente à Europa como se lhe não pertencêssemos ou fôssemos nela um caso à parte".

Com essas premissas em mente, faz-se a seguir uma breve leitura de trechos d'A jangada de pedra para ilustrar o posicionamento de Saramago quanto à aproximação com a Europa no contexto da entrada de Portugal na CEE. Depois se analisa o conceito de "imagologia", de Eduardo Lourenço, partindo do pressuposto de que configura um instrumento valioso para compreender certa visão coletiva do povo português acerca de si próprio. Num terceiro momento, colocando em relação imagologia e história, revisita-se parcialmente a história portuguesa para compreender quais seriam os traumas que ensejaram a imagética pessimista de um país aparentemente condenado a uma decadência irreversível. Produz-se, por fim, uma crítica do próprio conceito de imagologia, e em particular o da imagologia portuguesa, com a consequente atenuação do caráter pessimista das imagens por ela criadas. Esta análise contrapõe-se à perspectiva saramaguiana e pretende questionar percepções estabelecidas acerca do percurso histórico de Portugal no seu diálogo com a Europa. 


\section{Qualquer destino, exceto a Europa: Saramago e a jangada imaginária}

O romance A jangada de pedra foi lançado em 1986. Trata-se de uma narrativa insólita em que a península ibérica, após uma ruptura geológica inexplicável, destaca-se do resto da Europa, na fronteira entre a Espanha e a França, e põe-se a derivar pelo Oceano Atlântico. O enredo acompanha tanto as repercussões políticas e sociais deste evento apocalíptico quanto a história de cinco personagens que se encontram na "jangada" durante sua navegação rumo ao desconhecido. Os protagonistas têm origens diversas, embora pertençam todos ao espaço ibérico, sendo três deles portugueses (Joana Carda, Joaquim Sassa e José Anaiço), um espanhol (Pedro Orce) e uma originária da Galiza (Maria Guavaíra). O destacamento da península e outros eventos estranhos associados aos personagens provocam o encontro destes, que passam a empreender, eles mesmos, uma viagem no interior da jangada em movimento.

O presente trabalho não tem como objetivo esmiuçar o fio narrativo da obra ou mesmo interpretá-la. O romance é, antes, o ponto de partida para uma discussão sobre a identidade da nação portuguesa. A narrativa de Saramago, nesse sentido, é permeada de referências, críticas, posicionamentos e ácidas alusões do autor direcionadas aos europeus que se encontram do outro lado dos Pirineus. Embora as obras do Prêmio Nobel, incluindo esta, sempre deem ensejo a reflexões de natureza filosófica, política ou social, não há como deixar de apontar o fato de que o livro é publicado um ano após a assinatura do tratado de adesão de Portugal à CEE - ano de efetivo ingresso na Comunidade.

Há consenso entre os autores que estudaram o texto saramaguiano no sentido de ver no romance, entre as interpretações possíveis, uma resposta ou uma reflexão do autor sobre a associação de Portugal e Espanha ao espaço comunitário europeu. Com esta premissa em mente, emerge da narrativa uma noção peculiar sobre a nação portuguesa e sua posição no desenho da Europa. Assim é que, no início do texto, quando o destacamento da península ainda não se deu por completo e geólogos franceses e espanhóis discutem a natureza da gigantesca fenda surgida na fronteira, começa-se a vislumbrar algumas das visões de Saramago. Após um jornalista galego ter feito, no meio das discussões, uma pergunta ("para onde vai esta água?"), segue-se o seguinte trecho:

Era então o tempo em que discutiam, com ciência brusca e seca, os geólogos de ambas as partes (...) Sendo a voz galega, portanto discreta e medida, abafaram-na o rapto gaulês e o rompante castelhano, mas depois outros vieram repetir o dito arrogando-se 
vaidades de primeiro descobridor, aos povos pequenos ninguém dá ouvidos, não é mania da perseguição, mas histórica evidência. (SARAMAGO, 2015, p. 25)

Esta relação desigual de poder, que aqui se expressa como um mero ditado, ganha intensidade à medida que a península se distancia do continente, e sobretudo quando o foco da desigualdade é justamente o relacionamento entre os povos peninsulares e o restante da Europa:

Os europeus, desde os máximos governantes aos cidadãos comuns, depressa se tinham acostumado, suspeita-se que com um inexpresso sentimento de alívio, à falta das terras extremas ocidentais, e se os novos mapas, rapidamente postos em circulação para a atualização cultural do popular, ainda causavam à vista um certo desconforto, seria tão-somente por motivos de ordem estética, aquela indefinível impressão de mal-estar que ao tempo há-de ter causado, e ainda hoje nos causa a nós, a falta de braços na Vénus de Milos. (SARAMAGO, 2015, p. 163)

\section{Num trechologo a seguir, ede modo ainda mais incisivo, escreve Saramago:}

Ainda que não seja lisonjeiro confessá-lo, para certos europeus, verem-se livres dos incompreensíveis povos ocidentais, agora em navegação desmastreada pelo mar oceano, donde nunca deveriam ter vindo, foi, só por si, uma benfeitoria, promessa de dias ainda mais confortáveis, cada qual com seu igual, começámos finalmente a saber o que a Europa é, se não restam nela, ainda, parcelas espúrias que, mais tarde ou mais cedo, por qualquer modo se desligarão também. Apostemos que em nosso final futuro estaremos limitados a um só país, quinta-essência do espírito europeu, sublimado perfeito simples, a Europa, isto é, a Suíça. (SARAMAGO, 2015, p. 164-165)

Todos estes excertos ilustram uma imagem de distanciamento e de incompreensão entre os povos da península e o resto da Europa. Percebe-se que, ao menos na visão de Saramago, o olhar atribuído à Europa além-Pirineus e voltado para a Ibéria é um olhar de superioridade, quase de desprezo por povos "incompreensíveis", diferentes e, talvez, até "menores". Ao longo da obra, repetem-se à exaustão trechos desta natureza. A península ibérica é, sob tal perspectiva, objeto de repúdio e rejeição,

sendo que os governos europeus, que no passado nunca verdadeiramente mostraram querer-nos consigo, vêm agora intimar-nos a fazer o que no fundo não desejam e, ainda por cima, sabem não nos ser possível. Lugar indesmentível de história e cultura, a Europa, nestes dias conturbados, mostra, afinal, carecer de bom senso. (SARAMAGO, 2015, p. 174)

A hipérbole é um recurso literário legítimo, e se reconhece a genialidade do seu emprego nas obras do autor português. Saramago a utiliza, no entanto, para ilustrar um posicionamento ideológico real, que não lhe toca 
exclusivamente a ele - o escritor José Saramago - e que parece constituir uma determinada forma de pensar coletiva, uma autoimagem de Portugal na sua relação com países da Europa. Tendo-a como fundamento de sua posição, o autor defende implicitamente a rejeição da Europa, ou, transpondo-se a tese do romance para o momento histórico pertinente, a rejeição do ingresso de Portugal na CEE.

A própria CEE, aliás, se manifesta no romance quando emite uma declaração de apoio à península. O que chama a atenção, no entanto, são os bastidores da reunião que deságua nesse apoio:

Esta declaração, objetivamente clara, foi o que resultou de um aceso debate no seio da comissão, em que alguns países membros chegaram a manifestar um certo desprendimento, palavra sobre todas exata, indo ao ponto de insinuar que se a Península Ibérica se queria ir embora, então que fosse, o erro foi tê-la deixado entrar. (SARAMAGO, 2015, p. 45)

José Saramago produz em muitos dos seus romances o que Linda Hutcheon denominou de metaficção historiográfica, ${ }^{1}$ uma maneira de refletir sobre a história por meio da ficção, ou uma maneira de ficcionalizar a história, alterando suas verdades estabelecidas. Nas palavras de João Valente Aguiar e Nádia Bastos, trata-se de uma "ficcionalização do real histórico" em que são trazidos "processos históricos para dentro da obra de arte como pano de fundo e como construção ficcional concreta" (AGUIAR; BASTOS, 2010, p 22). No caso d'A jangada de pedra, a história de Portugal está presente justamente enquanto pano de fundo da narrativa, seja pelos sentimentos por ela gerados no imaginário português, seja na imagem de dois países que novamente se dirigem ao mar em busca de sua identidade - uma referência clara à grandeza de Portugal e Espanha na Era dos Descobrimentos.

O próprio Saramago, em artigo publicado no semanário Nova Gente, admitiu que seus livros são uma tentativa de responder à pergunta: o que é ser português? (AGUILERA, 2010, p. 103). De fato, A jangada de pedra também pode ser lida como um "questionamento acerca de Portugal e dos portugueses no concerto das nações" (NASCIMENTO, 2014, p. 154), com um posiciona-

\footnotetext{
1 Segundo a autora, "a metaficção historiográfica refuta os métodos naturais, ou de senso comum, para distinguir entre o fato histórico e a ficção. Ela recusa a visão de que apenas a história tem uma pretensão à verdade, por meio do questionamento da base dessa pretensão na historiografia e por meio da afirmação de que tanto a história como a ficção são discursos, construtos humanos, sistemas de significação, e é a partir dessa identidade que as duas obtêm sua principal pretensão à verdade" (HUTCHEON, 1991 apud BOTELHO, 2011, p. 313).
} 
mento claro do escritor no sentido de dissociar seu país da "outra Europa", vista como cultura distinta, alheia ao ser ibérico dos povos da península. Saramago expressou em artigos e entrevistas o seu receio de que a aproximação com aquela Europa representasse a "morte da cultura"2 portuguesa, chegando a afirmar peremptoriamente, numa entrevista concedida ao Diário de Lisboa, em 1982, que o futuro de Portugal não passava "com certeza, pela CEE", e arrematando: "nada temos a ver com a Europa" (AGUILERA, 2010, p. 441). Em outra ocasião, disse ainda: "não tenho nenhum interesse em me tornar europeu, não me apetece" ${ }^{3}$

Esta postura ilustraria, no imaginário do escritor - mas também, como se verá a seguir, no inconsciente coletivo português - certas preconcepções acerca da identidade portuguesa, em que Portugal parece se enxergar como uma espécie de "patinho feio" da Europa, ou como seu "primo pobre". Portugal, tendo em vista sua história, na qual, por longo período, voltou as costas para a Europa, criando uma identidade associada às glórias e aos descobrimentos marítimos, bem como ao contato com a África, as Índias e a América Latina, teria, no seu retorno à humilde "casa lusitana", criado uma espécie de complexo bipolar, gerando a dúvida sobre seu lugar no mundo. Afinal, Portugal é Europa ou não é Europa? Seu destino associa-se ao destino europeu ou não? Compreender este meio do caminho que parece ocupar Portugal é um dos pontos centrais do presente artigo.

Um dos autores portugueses que mais se debruçaram sobre o tema da identidade portuguesa foi Eduardo Lourenço. Como afirma Naira Almeida Nascimento (2014, p. 162), Saramago e Lourenço representam, pela via da ficção e do ensaio, "modos de ler a casa lusitana no mundo e em seu diálogo consigo mesma". Por esta razão, vale a pena revistar o pensamento de Lourenço para, em seguida, adentrar as razões históricas que ensejaram o nascimento de visões tão pessimistas acerca de Portugal no concerto das nações europeias.

\footnotetext{
2 Em entrevista concedida ao La Verdad, em 1994, diz Saramago: “a União Europeia dita-nos o que devemos fazer em todos os campos da vida. Encaminhamo-nos para a pior das mortes: a morte por falta de vontade, por abdicação. Esta renúncia é também a morte da cultura" (apud AGUILERA, 2010, p. 106).

3 "A jangada de Saramago", Vida Mundial, Lisboa, 7-14 de junho de 1989 (apud AGUILERA, 2010, p. 105).
} 


\section{Dois destinos, um país: Portugal e sua imagologia}

Eduardo Lourenço trabalha com o conceito de imagologia, que ele define como sendo "um discurso crítico sobre as imagens que de nós mesmos temos forjado" (2018a, p. 18). A imagologia é, portanto, uma autoimagem coletiva. No caso de Portugal, uma maneira coletiva de interpretar o que é ser português. Segundo Lourenço (1994, p. 10), o país nunca sofreu propriamente uma crise de identidade, a exemplo do que ocorre em outros locais, como o País Basco, a Córsega, a Bélgica, a Irlanda ou a Catalunha, não representando o estatuto linguístico, o estatuto cultural ou a situação histórico-política problema de qualquer relevo para o português. ${ }^{4}$ Muito pelo contrário, sofreria o português o mal da hiperidentidade, afirmando o ensaísta ser difícil encontrar um país "tão centrado, tão concentrado, tão bem definido em si mesmo como Portugal" (LOURENÇO, 1994, p. 10).

Esta consciência identitária foi forjada ao sabor dos eventos históricos. A história alimenta a percepção que a nação portuguesa tem de si mesma, assim como esta percepção, interiorizada, produz ao seu próprio modo a "história futura". O nascimento de Portugal se dá sob o signo do milagroso e da fragilidade, ${ }^{5}$ tendo em vista a dificuldade em se compreender como esse território exíguo conseguiu livrar-se da absorção pelo vizinho espanhol. Esta ideia alimentará outras, como a de seu papel messiânico (cristão, nem precisa dizer) entre os povos - a "nação eleita" do Padre Antônio Vieira (LOURENÇO, 2018b, p. 20). São ideias aptas a explicar também certos comportamentos do povo português, seu indiferentismo, ${ }^{6}$ a condição humilde e as adversidades vividas com "inata paciência" e "infinita resignação" (LOURENÇO, 2018a, p. 59).

\footnotetext{
4 "A Espanha, logo ao lado, é claramente 'múltipla na sua relação consigo mesma'", diz ainda (LOURENÇO, 1994, p. 19).

5 "O sentimento profundo da fragilidade nacional - e o seu reverso, a ideia de que essa fragilidade é um dom, uma dádiva da própria Providência, e o reino de Portugal uma espécie de milagre contínuo, a expressão da vontade de Deus - é uma constante da mitologia, não só histórico-política, mas também cultural portuguesa" (LOURENÇO, 2018b, p. 12).

${ }_{6}$ Eduardo Lourenço enfatiza, sempre que possível, o fato de a perda das colônias africanas no século XX não ter gerado qualquer trauma semelhante à perda da Argélia no caso da França, que ainda hoje o ressente, o que representaria mais um traço dessa indiferença, assim como "a prodigiosa irrealidade da imagem e dos mitos que nos permitiam usufruir candidamente - num mundo em plena metamorfose - de que éramos senhores dos territórios desmedidos que no tempo da distracção (relativa) imperialista ocidental tínhamos podido guardar" (LOURENÇO, 1994, p. 13).
} 
Para além dessas características - meras ilustrações, já que a complexidade de um povo não pode ser captada pela menção a poucos traços de sua personalidade -, um dos tópicos centrais da imagologia portuguesa seria a existência de uma espécie de tensão entre o passado histórico de Portugal e seu presente, tensão que se expressa, por exemplo, na própria língua, com a invenção, peculiar e sem tradução precisa em outros idiomas, da palavra saudade. A tensão nasce da comparação entre o que foi Portugal no passado e o que é atualmente, e só surge após longos séculos de história e, mais uma vez, como decorrência desta.

É possível conceber este sentido de duplicidade de diferentes maneiras, porque o passado remete a um Portugal distinto e, numa perspectiva redutora, a um Portugal melhor. Assim, os polos da tensão não são simplesmente o passado versus o presente, mas o que esses tempos representam nos seus contextos próprios, ou seja, um Portugal (antes) imperial, (agora) nacional, ou um Portugal rico/pobre; glorioso/diminuído; poderoso/impotente; respeitado/desrespeitado; vanguardista/atrasado; progressista/decadente etc. E é claro, uma tensão que decorre naturalmente destas polaridades: um Portugal ultramarino ou europeu. É neste jogo de visões sobre sua identidade que se instala o impasse, porque a nação parece ter transitado de um ser europeu medieval para um não ser (europeu) na época das navegações, tendo que, por fim, voltar-se sobre si quando seu império ruiu. É nesse momento de retorno que nasce o conflito: a Europa não é mais a mesma - e Portugal também não.

Gislene Teixeira Coelho resume bem a questão ao afirmar que quando se estuda a história de Portugal,

vê-se que o que mais se salienta não é a falta de uma identidade própria, pelo contrário, é a falta de uma identidade europeia. Esse Portugal-ilha experiencia uma sensação de estranhamento, sentindo-se como um estrangeiro em sua própria terra. Ser estrangeiro dentro da Europa faz da Península Ibérica uma outra Europa, politicamente e economicamente marginalizada. Pensando especialmente o caso português, observa-se que a nação não deseja ser ou resgatar a imagem da Europa esplendorosa, mas deseja ser reconhecida e afirmar sua diferença e sua particularidade dentro do grupo europeu. Portugal não convive com problemas de afirmação da identidade portuguesa, mas apresenta conflitos no que tange a sua identidade europeia, sejam eles advindos do não compartilhamento de valores culturais, do afastamento territorial ou do sentimento de rejeição por parte do Europeu, tudo isso conflui para criar uma situação de exclusão e apartamento. (COELHO, 2013, p. 5)

No que se refere ao relacionamento com a Europa, esta imagologia, segundo Lourenço, produz "um psicodrama de um só personagem em duas versões, ao mesmo tempo opostas e complementares", que ele traduz pelas noções de 
fascínio e ressentimento (1994, p. 25). De fato, ao encarar a Europa ao qual um dia pertenceu, antes de ter-se voltado para o Atlântico, Portugal tende a não reconhecer seu lugar no espaço geográfico continental, ainda que, para espanto dos que estudam a Europa de longe, não faça sentido falar de Portugal e Europa, porque Portugal - aos olhos de um brasileiro, por exemplo - é Europa. Esta disjuntiva (Portugal e Europa) revela, segundo Lourenço (1994, p. 25),

a consciência de uma distância, de uma marginalidade, talvez sobretudo, de uma como que fatal dependência ou inferioridade do tipo de cultura, e dos exemplos que a ilustram no seu nível mais elevado, quando a consideramos nessa espécie de espelho abstracto mas singularmente mágico onde brilham, como dizia Charles du Bos, as estrelas fixas do céu cultural europeu, Dante, Petrarca, Shakespeare, Cervantes, Rousseau, Goethe, Dickens, Tolstoi, Proust, autores de universal irradiação e leitura.

Observadas as coisas por este ângulo, é fácil concluir que Saramago, n'A jangada, encontra-se claramente vinculado ao "partido" do ressentimento. A acidez de seus comentários, quando se referem à Europa, não deixa margem a dúvidas. Mas que fatos históricos proporcionaram a formação desta autoimagem depreciativa? Posto o problema na perspectiva de Antero de Quental, quais seriam os fatores da decadência de Portugal e Espanha? As palavras não são neutras, e é necessário se perguntar não só se houve de fato decadência como também qual seria a natureza desta. Mais desafiador ainda seria questionar a própria operacionalidade e segurança de um conceito como o de imagologia para se compreender o desenrolar histórico. Afinal, é de se perguntar se o ressentimento - ou o fascínio - não teria a capacidade de turvar a visão da história ou de interpretá-la com graus exagerados de passionalidade.

\section{Os traumas portugueses: história e imagem em interação}

Traçaremos um breve e muito parcial esboço da história de Portugal a partir de uma lógica de ascensão e queda, no intuito de compreender a criação desta autoimagem pessimista do país em face de si mesmo e da Europa, imagem que só se consolida de fato e é expressa de modo pungente no século XIX, com a produção intelectual da famosa Geração de 70, embora Eduardo Lourenço reconheça que o sentimento de decadência é antigo e se inicia no momento em que Espanha e Portugal deixam de desempenhar os 
papeis dominantes que tinham sido os seus no período glorioso das descobertas marítimas. ${ }^{7}$

Dentro desse quadro conceitual, é preciso lembrar que apesar de a experiência portuguesa com o mar ter se iniciado bem antes, a expansão marítima só começa de modo sistemático no século XV, avançando-se paulatinamente as expedições pela costa africana com o objetivo de chegar às Índias. A experiência com a navegação e a respectiva expansão de Portugal produzem inúmeras consequências cujo teor são de enaltecimento do Estado e do povo portugueses. O país transforma-se na maior potência do Oceânico Índico até 1640, segundo A. H. de Oliveira Marques (2009), tornando-se o português a "língua franca do comércio" até o século XVIII (MARQUES, 2009, p. 324). Portugal, além disso, encontra-se na vanguarda de certos conhecimentos científicos, em particular no campo da geografia, da astronomia, da matemática, das ciências naturais e das técnicas náuticas, chegando os portugueses a provar, "pela experiência e pela dedução científica", que

o Oceano Atlântico era navegável e estava livre de monstros; que o mundo equatorial era habitável e habitado; que era possível navegar sistematicamente longe da costa e conseguir perfeita orientação pelo Sol e pelas estrelas; que a África tinha uma ponta meridional e que existia um caminho marítimo para a Índia; que as pseudo-Índias, descobertas por Colombo, eram, na realidade, um novo continente separando a Europa da Ásia oriental, e que as três Américas formavam um bloco territorial contínuo; que a América do Sul tinha uma ponta meridional como a África e que existia um outro caminho marítimo para a Índia por ocidente; que os três oceanos comunicavam entre si; que a terra era redonda e circum-navegável. (MARQUES, 2009, p. 186-187)

Despiciendo seria demonstrar o quanto essas circunstâncias não só contribuíram para gerar significativos lucros comerciais para o Estado português e os agentes envolvidos na expansão como contribuíram para a consolidação de uma autoimagem extremamente emuladora dos brios nacionais. Este Portugal que corajosamente se lança ao mar, dando as costas à Europa, não era "o sonhador de si mesmo" (LOURENÇO, 2018b, p. 17) que viria a ser no futuro; ele detinha de fato um império - autoimagem e realidade andavam de mãos dadas. Era de fato o Portugal cantado pelo gênio de Camões, e sua glória uma "glória merecida", que nas palavras de Antero de Quental, "só dava lugar à admiração" (2017, p. 45).

7 Lourenço faz esta afirmação no prefácio da obra de Antero de Quental, Causas da Decadência dos povos peninsulares nos três últimos séculos (QUENTAL, 2017, p. 23). 
O próprio Antero, contextualizando o período estudado e já com a dose de saudosismo que caracteriza um tempo diverso, assim se manifesta:

As descobertas, que coroaram tão brilhantemente o fim do século $\mathrm{XV}$, não se fizeram ao acaso. Precedeu-as um trabalho intelectual, tão científico quanto a época o permitia, inaugurado pelo nosso infante D. Henrique, nessa famosa escola de Sagres, de aonde saíam homens como aquele heroico Bartolomeu Dias, e cuja influência, directa ou indirectamente, produziu um Magalhães e um Colombo. Foi uma onda, que levantada aqui, cresceu até ir rebentar nas praias do novo mundo. Viu-se de quanto eram capazes a inteligência e a energia peninsular. Por isso a Europa tinha os olhos em nós, e na Europa a nossa influência nacional era das que mais pesavam. Contava-se para tudo com Portugal e Espanha. O Santo Império alemão oferece a orgulhosa coroa imperial a um rei de Castela, Afonso, o Sábio. No século XV, D. João I, árbitro em várias questões internacionais, é geralmente considerado, em influência e capacidade, como um dos primeiros monarcas da Europa. (QUENTAL, 2017, p. 43)

As circunstâncias históricas, no entanto, começam a mudar, e a concorrência de outros Estados dificultam a manutenção das posses portuguesas, de modo que em 1655, o poderoso império da Ásia estava reduzido a Goa, Damão, Diu, Baçaim e "meia dúzia de insignificantes fortalezas na Índia, a Macau na China e a metade de Timor, na Indonésia" (MARQUES, 2009, p. 311). A perda progressiva dos territórios coloniais, que só se consumará definitivamente no século XX, configura tão somente um dos muitos episódios traumáticos da história portuguesa a partir do século XVII. Embora não se possa falar de qualquer percurso histórico como constituído unicamente de traumas, ${ }^{8}$ vale a pena relembrar os episódios mais significativos do declínio português, considerando-se aqui "declínio" como perda de poder econômico e de influência política nos negócios do mundo.

Pensamos ser legítimo considerar que a derrota em Alcácer Quibir, em 1578, a morte de D. Sebastião e o consequente período de União Ibérica são os eventos que, associados à concorrência crescente na luta por territórios coloniais, marcam uma transição na história de Portugal. Com a união à

\footnotetext{
${ }_{8}^{8}$ Basta considerar, no caso de Portugal, que apesar da perda dos territórios asiáticos, ainda lhe restavam os territórios africanos e a "solução Brasil", que durante boa parte de sua história lhe trará lucros consideráveis, em particular no período da descoberta e extração do ouro em Minas Gerais, do final do século XVII à primeira metade do XVIII. Assim é que, até 1808, lembra A. H. de Oliveira Marques (2009, p. 362), as receitas totais do Estado português, por exemplo, não pararam de subir, e o país "achava-se sem dúvida mais rico nos começos do século XIX do que em qualquer outro tempo de sua História".
} 
Espanha, o país, de alguma forma, torna-se invisível para a Europa (LOURENÇO, 1994) e o posterior retorno à autonomia já não se dá nas mesmas condições. Por um lado, torna-se necessário, para "salvar o Brasil" das ambições holandesas e outras, "abandonar a Índia" (MARQUES, 2009, p. 329). . Não era possível, para um país de limitadas capacidades como Portugal, lutar em todas as frentes e defender um império tão vasto. Por outro lado, o Estado português sai da esfera de dominação espanhola para cair na inglesa. "A situação desesperada de um país que lutava pela sua independência", lembra A. H. de Oliveira Marques (2009, p. 255), levou o país "à assinatura de diversos acordos claramente opressivos do comércio nacional". Esta tutela inglesa se tornará cada vez mais sufocante, atingindo seu auge no final do século XIX, ao ponto de João Martins Pereira (1971, p. 56) afirmar que

no auge da era vitoriana, o então chamado "Império Português" era, economicamente, uma autêntica parcela do muito mais vasto Império Britânico, daí resultando naturalmente uma dependência política que, em certos momentos, veio a público através de episódios que não deixavam margem a dúvidas. ${ }^{10}$

Um desses episódios foi o execrável Ultimatum Britânico de 1890, em que, no contexto da corrida pela conquista da África, Portugal é obrigado a renunciar ao território que entendia como seu, localizado entre Angola e Moçambique. A Inglaterra demonstrava abertamente até que ponto ia a "amizade" com seu protegido, provocando grande indignação em Portugal e, inclusive, um movimento generalizado contra a monarquia portuguesa, responsabilizada então pelo descaso com que tratara a questão dos territórios ultramarinos (MARQUES, 2009).

Cronologicamente anterior ao ultimatum, não se pode esquecer do trauma decorrente das invasões napoleônicas, em que Portugal foi ocupado durante três anos. Não há melhor palavra para expressar um sentimento do que "trauma" neste caso. Portugal, segundo Lourenço (2018b, p. 28), "experimentou-se então como um povo jogado aos dados". É preciso lembrar, para

\footnotetext{
9 Estratégia semelhante será adotada no século XIX. Depois de perdido o Brasil e com o aumento das pretensões imperialistas de outros países na África, Portugal, que, à exceção de Angola, nunca planejara efetivamente a ocupação de suas posses africanas, começa a tomar medidas neste sentido (MARQUES, 2009). Diz A. H. de Oliveira Marques (p. 523) a este sujeito que "o que levou Portugal à conquista de Angola, Moçambique e Guiné foi sobretudo a concorrência estrangeira e o receio crescente de ser roubado daquilo que considerava território seu".

${ }^{10}$ Também A. H. de Oliveira Marques expressa ideia semelhante ao dizer que “de 1808 a 1821, o país passou a ser, quer um protectorado inglês, quer uma colónia brasileira" (MARQUES, 2009, p. 400).
} 
compreender a extensão do dano em termos de autoimagem, que a "situação era insólita para uma velha nação que nunca fora partilhada nem objecto de olhar alheio, mas actor, ainda que diminuído, de vida própria" (LOURENÇO, 2018b, p. 28). Não bastasse o ineditismo de ter um invasor no seu território e a fuga da corte para o Brasil, as consequências das invasões são desastrosas:

\begin{abstract}
Quatro anos de guerra haviam deixado o país em situação miserável. As invasões e a ocupação francesas devastaram boa parte de Portugal, sobretudo a norte do Tejo. A agricultura, o comércio e a indústria foram profundamente afectados, já sem falar das perdas em vidas e das destruições sem conto. Tanto franceses quanto ingleses saquearam bom número de mosteiros, igrejas, palácios e casas humildes, levando consigo toda casta de objectos preciosos, incluindo quadros, esculturas, móveis, joias, livros e manuscritos. Num país pequeno como Portugal, tais perdas sentiram-se profundamente. (MARQUES, 2009, p. 400)
\end{abstract}

Com o devido recuo no tempo, coube à Geração de 70, um grupo ativo de intelectuais que tinha como uma de suas propostas "repensar Portugal, como Nação e como Cultura" (PEREIRA, 2007, p. 9), e em particular a Antero de Quental, ser a porta-voz da decadência portuguesa. Além desses episódios, que certamente já faziam parte do imaginário português, Antero, no contexto das Conferências do Casino, em maio de 1871, vem elencar um conjunto de causas estruturais para explicar o declínio português. São elas de natureza política, moral e econômica. Os ataques de Antero (QUENTAL, 2017) recaem basicamente sobre a Igreja Católica e o Concílio de Trento, que obstaculizaram a reforma religiosa ocorrida em outros estados europeus e a consequente liberdade de pensamento que estava na base da circulação do conhecimento científico e do crescimento de uma classe média; o estabelecimento do Absolutismo, que tolheu as liberdades locais dos povos ibéricos; e o desenvolvimento das conquistas de ultramar. ${ }^{11}$

Correndo o risco de alongar demasiadamente este tópico, não resistimos à tentação de citar o próprio Antero, apesar da extensão do trecho, pela sua pertinência, pela visão afiada e humanista do escritor, e pela desenvoltura literária de seu texto:

\footnotetext{
${ }^{11}$ Causa impressão o quanto Antero, neste ponto ainda mais do que nas ferozes críticas à Igreja Católica, estava à frente de seu tempo. Quando o imperialismo ainda era um dado da época, já dizia, com extrema clarividência: "Há dois séculos que os livros, as tradições e a memória dos homens andam cheios dessa epopeia guerreira, que os povos peninsulares, atravessando oceanos desconhecidos, deixaram escrita por todas as partes do mundo. Embalaram-nos com essas histórias: atacá-las é quase um sacrilégio" (QUENTAL, 2017, p. 79-80).
} 
Não só deixamos de exportar, mas passamos a importar: "do reinado de D. Manuel em diante", diz Alexandre de Gusmão, "somos sustentados pelos estrangeiros". Esse sustento podiam-no pagar os grandes, que a Índia e o Brasil enriqueciam. A multidão, porém, morria de fome. A miséria popular era grande. A esmola à portaria dos conventos e casas fidalgas passou a ser uma instituição. Mendigavam aos bandos pelas estradas. A tradição, num símbolo terrivelmente expressivo, apresenta-nos Camões, o cantor dessas glórias que nos empobreciam, mendigando para sustentar a velhice triste e desalentada. É uma imagem da nação. As crónicas falam-nos de grandes fomes. Por tudo isto, decrescia a olhos vistos a população. Que remédio se procura a este mal? Um mal incomparavelmente maior: a escravidão! Tenta-se introduzir o trabalho servil nas culturas, com escravos vindos da África! Felizmente, não passou de tentativa. Era a transformação dum país livre e civilizado numa coisa monstruosa, uma oligarquia de senhores de roça! A barbaridade dos devastadores da América, transportada para o meio da Europa! Com estes elementos, o que se podia esperar da indústria? Uma decadência total. Não se fabrica, não se cria: basta o ouro do oriente para pagar a indústria dos outros, enriquecendo-os, instigando-os ao trabalho produtivo, e ficando nós cada vez mais pobres, com as mãos cheias de tesouros. (QUENTAL, 2017, p. 84-85)

É de se perguntar o que restava a Antero, após tal diagnóstico, senão tornar-se o "iberista federalista convicto" que Eduardo Lourenço o acusa de ser (2018a, p. 94). É nesse contexto e com reflexões dessa natureza que a Europa além-Pirineus parece surgir ante o olhar ressentido dos ibéricos como outra Europa, ou melhor, que a noção de Europa passa a não incluir mais Portugal e Espanha, pois começa a ser vista como algo muito distinto, um espaço tecnológico, econômico, cultural e cientificamente mais avançado. É a partir de então que cresce a obsessão em "europeizar Portugal" (LOURENÇO, 1994, p. 30), cabendo à Geração de 70, na visão que tinha de seu papel e segundo o magistério de Eduardo Lourenço (2018a, p. 91), "recuperar (...) esse atraso demencial, que, segundo o diagnóstico do mais precoce dos seus gênios tutelares, se cavara ao longo de três séculos, entre um povo, farol dos mundos, e o mesmo povo agora convertido na lanterna vermelha das nações civilizadas".

Em semelhante contexto, nada mais natural que ganhem força as posições defensoras do Iberismo, uma corrente de pensamento à qual José Saramago também se filiava, e um fruto da convicção de que a decadência portuguesa era "inevitável e progressiva" (FRAGA, 1991, p. 240). Embora as tentativas de união entre Espanha e Portugal remontem a um passado distante e estejam associadas ao imaginário do território da Hispânia pagã dos romanos (MARQUES, 2009), no século XIX esta discussão volta à tona com maior vigor.

António Bartolomeu Ferreira classifica o Iberismo em três tipos: o monárquico, o federalista e o cultural (JUSTO, 2008). Se Antero era um adepto da espécie federalista, como forma de combater a decadência por ele diag- 
nosticada, a posição de Saramago é mais ambígua. Parece estar vinculada ao Iberismo cultural, que, ainda segundo Bartolomeu Ferreira, é de "carácter não político" e encontra sua base num "conjunto de aportações intelectuais dos dois países no sentido de resumir a aspiração ideal à associação das diferentes tendências de pensamento na península" (JUSTO, 2008, p. 202-203). Seja como for, o Iberismo configura uma corrente de pensamento contra a qual se podem levantar diversas críticas, além da evidente "solução de desespero" - ou "solução de desespero à Antero", como Lourenço a apelidou (2018a, p. 82) - que parece representar.

Não há dúvida, para começar, de que o Iberismo é fruto de uma visão elitista, absolutamente dissociada do sentimento do povo português. ${ }^{12}$ Cinco séculos de governo próprio haviam forjado a nação portuguesa (MARQUES, 2009), consolidando o sentimento de nacionalidade, sendo a noção de identidade nacional, segundo José Mattoso, aparentemente "precoce e suficientemente clara desde a primeira metade do século XIII" (MONTEIRO; PINTO, 2005, p. 53). O próprio Antero reconhece a antipatia do povo pela ideia quando diz, em carta a Oliveira Martins, que o "iberismo não se-há de realizar nem pela simpatia mútua, nem pelo convencimento, mas pela força e necessidade das coisas. Os portugueses hão-de-ser sempre refractários a tal ideia" (FRAGA, 1991, p. 242). O período de União Ibérica, ademais, ainda que nos seus primórdios não tenha sido tão questionado, revelou-se, por fim, insustentável ante a centralização espanhola e as consequências negativas decorrentes do seu jugo. ${ }^{13}$

O fato é que o relacionamento entre Portugal e Espanha nunca foi baseado na confiança. Desde o período conturbado de criação do Estado português, passando por episódios romanescos como o da influência castelhana de Inês de Castro sobre o príncipe D. Pedro, a Espanha sempre foi encarada como um "sócio perigoso", na expressão de A. H. de Oliveira Marques (2009,

\footnotetext{
${ }^{12}$ José Manuel Sobral desenvolve uma interessante análise para provar que a maioria da população era, de fato, contra a união. Aponta como indícios, além dos trabalhos históricos produzidos sobre o tema, o teor das pregações e dos sermões eclesiásticos, a importância do sebastianismo e as ações populares, em particular as revoltas contra os impostos no final da união ibérica, em que ocorrem "manifestações claras de hostilidade ao castelhano/espanhol" (SOBRAL, 2012, p. 53-54).

${ }^{15}$ Para uma análise das crises atravessadas pelos dois países na fase final da União Ibérica, com consequente aumento de impostos em território português, perseguição de portugueses em colônias espanholas e outras ações impopulares do Estado espanhol, que provocavam a indignação de Portugal contra o vizinho, ver as reflexões de A. H. de Oliveira Marques nas páginas 285-298 (MARQUES, 2009).
} 
p. 462). Esta desconfiança é objeto até de ditos populares - "da Espanha nem bom vento nem bom casamento" - e só se atenua de modo significativo no século XX - cúmulo da ironia, sobretudo quando os dois Estados decidem ingressar na CEE. ${ }^{14}$ Ainda assim, no contexto da integração de ambos os países na CEE, Nuno G. Monteiro e António Costa Pinto (2005, p. 63-64) chegam a afirmar que "falhadas as tentativas portuguesas de negociação autónoma de timings de integração na Comunidade, a Espanha emergiu periodicamente na opinião pública como um poderoso vizinho 'invadindo' Portugal".

Uma situação como esta gerou nos portugueses, inclusive, a noção de que a Espanha representava um obstáculo ao diálogo com outros países europeus. Entre a segunda metade do século XVII e o século XVIII, inicia-se, na lição de Antonio Rocamora (1993, p. 633), um "divórcio cultural, destinado a perdurar muito tempo, em virtude do qual espanhóis e portugueses se preocupam mais com a produção cultural para além dos Pirineus" enquanto ignoram aquela dos vizinhos ibéricos. É também a tese de A. H. Oliveira Marques quando ensina que

a partir do século XVIII Portugal deu-se conta de que seu lugar entre as nações civilizadas do globo e a sua individualidade como nação europeia dependiam da sua reação contra a Espanha. Pela primeira vez na história, e apesar de todas as lutas e afirmações culturais do passado, a unidade espiritual da Península Ibérica foi rompida, e com ela a possibilidade de uma união política viável. Portugal começou a encarar a Espanha como um obstáculo situado entre ele e o resto da Europa, qualquer coisa a obstruir o caminho, a impedi-lo de comunicar facilmente com a França e com os demais países. Gradualmente Portugal foi-se tornando menos ibérico e mais europeu. E a frustração portuguesa de isolamento e de distância acentuou-se também então. (2009, p. 378)

E que não se considere Saramago um pensador ingênuo que não estivesse a par desta distância - aqui sim, uma distância muito palpável - entre Portugal e Espanha. Em entrevista, o escritor já havia deixado claro que

Espanha e Portugal já se deveriam ter entendido há muito tempo. Pela parte de Portugal, numa direção que não fosse essa contínua suspeita em relação à Espanha, essa desconfiança secular. E pela parte da Espanha, pondo de lado essa espécie de complexo de

\footnotetext{
${ }^{14}$ Nesse sentido, lembra João Ferreira do Amaral que, até 1986, Portugal e Espanha viviam uma situação anômala para dois países vizinhos, "sem contenciosos políticos importantes, com um comércio subdesenvolvido entre si devido às elevadas barreiras comerciais. É só a entrada simultânea dos dois países na CEE que implicará, finalmente, na derrubada destas barreiras" (AMARAL, 2006, p. 118).
} 
amputação da parte lateral da Península. A verdade política é que somos uma península e dois países. Mas temo-nos mantido afastados. Portugal, porque "o mal sempre veio de Espanha". Espanha, por esse "complexo de amputação", porque quis ignorar a nossa existência. Isto é, de um lado sempre existiu o temor; do outro a indiferença, a ignorância. ${ }^{15}$

Esta relação conflituosa com a Espanha, não se pode olvidar, está na raiz da formação identitária portuguesa. José Manuel Sobral coloca a questão de modo muito pertinente ao dizer que "Castela será o Outro Significante, aquele que, pela sua maior proximidade, desempenha um papel crucial na construção, pela diferença, de uma identidade coletiva própria" (2012, p. 41). Por estas e outras razões, que ainda serão desenvolvidas, é que o Iberismo, ao menos na sua versão política, parece representar antes um desejo surreal, baseado numa profunda frustração de alguns setores políticos, ${ }^{16}$ do que um projeto que efetivamente pudesse um dia sair do papel $^{17}$ - a consequência, se poderia dizer, de se querer construir a história à base de sentimentos muitas vezes desvinculados dos fatos mais evidentes. Esta é, talvez, uma entre muitas das críticas que se pode fazer à própria noção de imagologia, objeto de discussão do próximo tópico.

\section{Imagologia e história: um sucinto balanço crítico}

Uma noção tão abstrata como a de imagologia não poderia ser aceita sem críticas. João Martins Pereira, embora reconheça o gênio de Lourenço, bem como os poderosos insights de sua visão acerca da mentalidade portuguesa, recusa a ideia de que se possa realizar a psicanálise de uma sociedade, qualquer que ela seja, a começar porque esta não é uma "entidade personalizável", como o indivíduo (PEREIRA, 1983). Critica também o pessimismo

\footnotetext{
15 "Saramago, o pessimista utópico", Turia, Teruel, $\mathrm{n}^{0}$ 57, 2001 (apud AGUILERA, 2010, p. 417).

${ }^{16}$ Rocamora fala no aparecimento do nacionalismo ibérico como uma "via para a superação dos problemas internos" dos países da península (1993, p. 648).

${ }^{17}$ Não se está a negar a existência de movimentos em prol do Iberismo, até mesmo a existência de um "nacionalismo ibérico", na expressão de Antonio Rocamora. O fato indiscutível, no entanto, é que estes movimentos aparecem como projetos fracos, sobretudo se comparados com o sentimento de identidade português aparentemente já consolidado nos principais momentos em que o Iberismo foi discutido com alguma seriedade. Ao falar da "onda iberista" surgida na década de 1860, Nuno G. Monteiro e Antonio Costa Pinto contrapõem "os vagos projetos de união dinástica peninsular", reconhecendo a timidez dessas manifestações ante o "fulgor nacionalista das décadas posteriores" (MONTEIRO; PINTO, 2005, p. 57), e José Manuel Sobral conclui que tais projetos "foram sempre muito minoritários entre as elites e nem sequer conhecidos das classes populares" (2012, p. 63).
} 
da análise de Lourenço, ao diagnosticar o português como um povo doente, bem como seus exageros para singularizar a nação (PEREIRA, 1983).

De fato, o que nos chama atenção no romance de Saramago é o tom exageradamente pessimista adotado para simbolizar a relação entre Portugal e o resto da Europa, um pessimismo cujas causas são, de alguma forma, explicadas por Lourenço, sem que este, no entanto, deixe de dar seu aval ao mesmo sentimento. Quanto a este tema, parecem estar alinhados Antero, Lourenço e Saramago, ao considerar, em grandes linhas, que Portugal se dissociou - em vários terrenos, que vão do econômico ao cultural - da Europa, mas de modo tão radical que o país não se reconheceria mais como um integrante desta mesma Europa que, não se pode negar, ele contribuiu para construir histórica, social, política e economicamente.

Um dos problemas é que, por representar uma imagem acerca do real, a imagologia, em grau muito maior do que a história, está sujeita a um aporte de subjetividade passível de viciar a compreensão dos fatos, inserindo muitas vezes as inclinações do sujeito na análise formulada sobre as relações históricas. Assim, nada mais significativo do que Saramago ter declarado, em entrevista ao Turia no ano de 2001, ser o romance $A$ jangada de pedra fruto de um "ressentimento histórico" (apud AGUILERA, 2010, p. 417), ${ }^{18}$ ou Lourenço demonstrar enorme surpresa ante a maneira natural como Portugal se integrava ao novo espaço europeu, passando-se tudo como se "o secular e tenaz contencioso histórico-cultural entre a Península e uma certa Europa tenha encontrado já uma solução, sem que a própria lembrança de tal contencioso (...) ensombre esta espetacular adaptação, quase se diria, conversão" (LOURENÇO, 1994, p. 53).

É que, para pôr as coisas em termos bem coloquiais, talvez esse contencioso estivesse mais nas mentes das elites do que na realidade dos fatos ou, para usar as frases lapidares do próprio Lourenço, talvez ele fosse mais imaginado do que real, sendo o diálogo entre as duas culturas (peninsular e europeia) "ficcional" (LOURENÇO, 1994, p. 58), e a referida disputa uma mera "querela onírica" (p. 166). Eis um dos riscos que se corre ao depositar tanta confiança na imagologia: eventos históricos podem atenuar ou até desmentir

\footnotetext{
${ }^{18}$ Pensamos que a história deveria, como disciplina, ser neutra - talvez um posicionamento ingênuo, já que sempre há um sujeito a narrar a história a partir de seus próprios condicionamentos. Se fatos deveriam ser meramente tratados como fatos, quando se imiscui no histórico uma noção tão pessoal e psicológica como a de "ressentimento", é duvidoso que o próprio julgamento dos eventos possa se distanciar da objetividade necessária à sua compreensão.
} 
toda uma elaborada abstração pretensamente capaz de captar a verdade sobre um povo. É a história a revelar suas próprias verdades, desmistificando e desconstruindo percepções secularmente consolidadas. E não se está a defender a inexistência dos traumas históricos portugueses ou a validade da imagologia de Lourenço. Apontamos simplesmente para o seu exagero e para algumas de suas fragilidades.

Assim como a essência da história é voltar-se para o passado, de modo a tentar explicar um tempo revoluto, a imagologia nasce da interiorização de sentimentos relacionados à história, mas com uma defasagem brutal com relação ao tempo em que se constitui. Explicamo-nos com um exemplo. É no mínimo estranho descobrir que na mesma época em que a Geração de 70 apontava para a decadência portuguesa, vivia-se em Portugal a experiência do Fontismo, uma "política adulta e amadurecida de obras públicas" que proporcionou ao país grandes avanços em termos de construção de estradas de ferro e desenvolvimento das comunicações (MARQUES, 2009, p. 490-491). Em outras palavras, a imagologia, como a história, remete ao passado, impossibilitada que está de captar as transformações do tempo presente, de maneira que, diante de ocorrências que não condizem com sua construção imagética, precisa curvar-se e reconhecer que algo passou despercebido - daí a surpresa de Lourenço com a adaptação rápida de Portugal ao espaço europeu.

O que parece ter passado despercebido, ou ao menos é amplamente ignorado nessa imagologia inspirada no pessimismo assombroso de Antero, são, por assim dizer, os laços que sempre existiram entre Portugal e essa Europa tão psicologicamente afastada dos portugueses. A história de Portugal está intrinsicamente ligada à Europa, e se este fato foi posto em dúvida algumas vezes, como à altura da discussão sobre o ingresso na CEE, razões circunstanciais parecem explicar melhor esta hesitação do que uma imagem de estranhamento. Fernanda Maria Ferreira Pinto, ao analisar a integração à CEE, explicita essa ideia ao dizer que o impulso para a Europa não representou mais que "o reforço de uma tendência que se foi evidenciando ao longo dos tempos, atravessando momentos de afastamento seguido de reaproximações ao sabor dos 'ventos' da história” (PINTO, 2011, p. 7).

Sem nos determos nos laços sanguíneos que sempre interligaram as monarquias europeias, por meio de casamentos entre membros das famílias reais, não se pode olvidar que Portugal, desde o século XV, foi o intermediário comercial, ponto de contato entre a Europa e a África; que em termos culturais, com o desenvolvimento do Humanismo no século XVI, houve intercâmbio intenso de professores nacionais e estrangeiros, com quantidade significativa de acadêmicos portugueses a lecionar na Itália, França e 
Inglaterra, entre outros países (MARQUES, 2009); que, como decorrência da percepção segundo a qual a Espanha representava um obstáculo cultural, estabelece-se a necessidade de "saltar por cima dela" para dialogar com o resto da Europa, em particular com a França (LOURENÇO, 1994); que toda a Europa professa, em sua generalidade e apesar das diversas igrejas, a religião cristã - enfim, a lista é praticamente sem fim.

O movimento migratório português também não pode ser menosprezado. Se no passado o país de destino foi o Brasil, nos anos sessenta do século XX ocorre uma "imigração maciça" para a França (PEREIRA, 1971), e embora esta imigração decorra de um aspecto negativo, qual seja, as condições econômicas precárias em Portugal, que terminam por "expulsar" seus nacionais em busca de melhores condições de vida, as influências recíprocas - entre o português e os nacionais do país receptor - promovem uma aproximação cultural que leva Eduardo Lourenço a dizer que

la vieille émigration était finie. Elle avait aidé, plus que tout autre phénomène, à la métamorphose du Portugal pauvre en Portugal désireux de se sentir plus à l'aise dans une Europe qui était maintenant son horizon incontournable, et où, paradoxe, nos émigrants, et, surtout, leurs enfants, commençaient à faire figure d'explorateurs, d'avant-garde, de premiers Portugais Européens à part entière, et non pas uniquement, comme nous l'étions depuis des siècles, des Portugais rêveurs d'Europe. (1994, p. 180) ${ }^{19}$

Inúmeros eventos históricos mostram-se aptos a demonstrar o quanto Portugal, por assim dizer, "sempre foi Europa", mas talvez dos mais significativos seja, apesar de suas limitadas capacidades, a participação portuguesa na Primeira Guerra Mundial. Parece complicado justificar tamanho distanciamento da Europa quando soldados portugueses estão a derramar sangue em nome dela. ${ }^{20}$

Mas a demonstração dos vínculos com a Europa não para por aí e poderia ser visualizada num período mais contemporâneo. É que, apesar da

\footnotetext{
19 "A velha imigração se findara. Ela havia contribuído, mais do que qualquer outro fenômeno, para a metamorfose do Portugal pobre em um Portugal desejoso de se sentir mais à vontade em uma Europa que era agora seu horizonte incontornável, e onde, paradoxo, nossos imigrantes e, sobretudo, suas crianças, começavam a representar o papel de exploradores de vanguarda, de primeiros Portugueses europeus completos, e não mais, unicamente, como nós fomos durante séculos, de portugueses sonhadores da Europa" (tradução nossa).

${ }^{20}$ Na Segunda Guerra Mundial, apesar da neutralidade portuguesa, Portugal se viu forçado a ajudar os Aliados, cedendo bases militares nos Açores à Inglaterra e aos Estados Unidos, por exemplo. Relembre-se também que Portugal foi membro fundador da Organização do Tratado do Atlântico Norte. A dúvida que nos assalta é se se pode ser mais europeu do que isto...
} 
posição de isolamento em que Portugal se encontrava devido ao regime ditatorial e à questão das colônias diante de uma Europa democrática, ${ }^{21}$ o Estado português não deixou de se relacionar com outros Estados europeus, firmando diversos tratados internacionais, de que são meros exemplos a Organização Europeia de Cooperação Econômica, em 1948, convertida posteriormente em Organização de Cooperação para o Desenvolvimento Econômico, e a Associação Europeia de Livre Comércio, uma iniciativa britânica que constituía resposta ao nascimento da Europa comunitária.

Esta constante interação, que abarca diferentes níveis (histórico, econômico, cultural e político) ao longo da história, induz à conclusão de que a aproximação de Portugal com a Europa não representa qualquer "viragem histórica" (PINTO, 2011, p. 20) significativa no relacionamento entre os dois, mas antes uma reaproximação. Se afastamento houve, pode-se dizer que foi em grande medida imaginário. A história continuava, para além de qualquer imagologia, a traçar de modo indissociável os destinos de Portugal e Europa, ou melhor, de Portugal na Europa.

\section{A título de conclusão: enfim - ou novamente -, a Europa!}

Não nos sobra espaço para falar do que Portugal é hoje - e para tentar decifrar qual seria, atualmente, a imagem que tem de si. Finalizamos com algumas considerações sobre o ingresso do país na CEE. Como em qualquer projeto de integração desta espécie, a entrada e manutenção de Portugal no bloco é uma história de altos e baixos. Estudos como o de Fernanda Maria Ferreira Pinto (2011) ou de João Ferreira do Amaral (2006) apresentam análises semelhantes acerca dessas variações, sem que estas circunstâncias, positivas ou negativas, representem o céu prometido por uma certa mitologia da Europa - a esperança de que ela seria "a solução para todos os problemas nacionais", segundo Fernanda Maria Ferreira Pinto (2011, p. 69) - ou o apocalipse cultural que parecia assombrar José Saramago.

\footnotetext{
${ }^{21}$ O principal fator a impedir a entrada de Portugal na CEE antes da revolução de 1974 talvez nem fosse a vontade de Salazar, mas a barreira formal instituída pelo bloco, que só permitia a entrada de países de regime democrático (PINTO, 2011). Fernanda Maria Ferreira Pinto afirma, em apoio a esta tese, que a partir de 1961 a ideia de adesão é "oficialmente admitida" pelo governo, desde que se pudesse conciliá-la com a estrutura política interna do regime. E conclui: "torna-se notório que o governo de Salazar pretendia usufruir das vantagens da integração europeia sem perder no entanto os benefícios da dominação ultramarina" (2011, p. 29-30).
} 
Traçando um breve retrospecto político, sabe-se que a solicitação de adesão ao Conselho da Europa, aceita rapidamente, se deu em 1976. Em 28 de março de 1977 ocorrem os pedidos formais de adesão tanto à CEE quanto à Comunidade Europeia do Carvão e do Aço e à Comunidade Econômica Eurasiática (PINTO, 2011, p. 69). O pedido de entrada na CEE se dá, portanto, só dois anos após a revolução de 1974, mas o processo de aceitação é longo, vindo o Tratado de Lisboa a ser assinado tão somente em 12 de junho de 1985, entrando em vigor em 1986, ano do lançamento do romance de José Saramago.

Esta demora poderia ser interpretada como mais um sinal de marginalidade e descaso pelos povos ibéricos, uma acusação a la Saramago, mas Fernanda Maria Ferreira Pinto lembra que a CEE mostrava-se cautelosa por outras razões: queria "certificar-se de que as instituições democráticas portuguesas funcionavam e funcionariam de forma regular", pretendia "resolver problemas internos antes de permitir a adesão de novos membros" e não queria "conceder a Portugal nenhum benefício transitório que pudesse prejudicar as relações paralelas com a Espanha" (2011, p. 40). ${ }^{22}$ O problema de se ter uma autoimagem internalizada vem à tona novamente: qualquer ocorrência histórica pode ser interpretada como uma confirmação do "desprezo europeu" para com Portugal e de sua condição periférica. Quando se buscam as razões históricas, a imagologia, às vezes, perde consistência.

Em termos de resultados, com base nos citados estudos, verifica-se que os primórdios da integração foram muito positivos para Portugal. A entrada na CEE ajudou a consolidar a democracia portuguesa, afastando, como previra Francisco Sarsfield Cabral, "tentações antidemocráticas internas" (1978, p. 39), e se traduziu em ajudas financeiras substanciais pelo Fundo Europeu de Desenvolvimento Regional (PINTO, 2011, p. 57), que contribuíram para o avanço e a modernização da sociedade. Os prazos conferidos ao país para se adequar à futura concorrência econômica de países mais desenvolvidos do bloco proporcionaram condições muito positivas para o conjunto da economia.

Quando a integração se aprofunda, há certo consenso de que a situação econômica declina como um todo. Portugal submete-se, então, a uma concorrência mais brutal e passa também a enfrentar as consequências da

\footnotetext{
${ }^{22}$ António Costa Pinto e Nuno Severiano Teixeira apontam, ainda, como motivos para a demora, "a situação econômica portuguesa imediatamente posterior à transição; a instabilidade governamental", bem como a "natureza política e constitucional do regime", em particular, neste último caso, a existência na constituição portuguesa de um órgão (o Conselho da Revolução) não democrático de natureza militar (2005, p. 36-37).
} 
entrada de novos parceiros na União Europeia, sobretudo em face da nova mão de obra mais barata, decorrente dos sucessivos alargamentos do bloco (PINTO, 2011). Em grandes linhas, pode-se dizer que o período de 1986 a 1991 foi de intenso crescimento, aproximando Portugal dos padrões de desenvolvimento de seus parceiros, período após o qual a atividade econômica se torna mais lenta (PINTO, 2011, p. 75-76). De 1995 a 2000, há uma nova fase de crescimento, seguida por recessões em 2003 e em 2009 (PINTO, 2011). Embora esta análise seja mais do que superficial, o que parece ter ocorrido é, em termos gerais, um ajustamento decorrente da participação nos processos de integração - altos e baixos na economia sempre haverá, seja com integrantes, seja com não integrantes de um bloco regional.

O que importa considerar é o enorme salto na qualidade de vida dos portugueses nas décadas que se seguiram ao 25 de abril e ao ingresso na CEE (PINTO, 2011). Este salto, confirmado pelos estudiosos da evolução econômica portuguesa e visivelmente notado pelos indivíduos que presenciaram a transformação, em boa medida se deve à sua inserção democrática no mercado europeu e nos quadros institucionais da Europa. Alguns setores, como sempre ocorre em processos desta natureza, foram evidentemente prejudicados nessa inserção devido às suas debilidades estruturais. No entanto, parece razoável considerar que Portugal é hoje um país "diferente para melhor" (PINTO, 2011, p. 118). ${ }^{23}$

Eduardo Lourenço, mal recuperado, aparentemente, do seu espanto com a adaptação portuguesa ao novo cenário europeu, nota esta transformação ao afirmar, em 1994 (p. 168), que "um país de dez milhões de habitantes que recebe anualmente vinte milhões de turistas - a maior parte europeus - não pode mais se ver visto, como no século XIX, como a Patagônia da Europa". ${ }^{24}$ Apesar do seu diminuto território, que inevitavelmente coloca Portugal numa posição economicamente inferior à de seus parceiros mais poderosos, não resta dúvidas de que o atrelamento à Europa contribuiu bastante para melhorar as condições de vida do país, em todos os âmbitos.

\footnotetext{
${ }^{23}$ Também não se está a afirmar que o é tão somente em razão da entrada no bloco, uma vez que não há possibilidade de se separar a variável europeia de outras variáveis associadas à evolução da sociedade portuguesa como um todo. O que se pode dizer é que a participação no projeto europeu contribui significativamente para o melhoramento da situação anterior.

${ }^{24}$ Inúmeros dados poderiam ser trazidos à tona para comprovar o quanto Portugal se desenvolveu nos últimos cinquenta anos, mas o tema é vasto e ultrapassa as pretensões do artigo. Ademais, deixaria de ser propriamente um estudo histórico, dada a dificuldade, e até recusa, que tem a disciplina em lidar com eventos tão contemporâneos à sua produção.
} 
O que dizer da imagologia saramaguiana, sem querer exigir dela que predissesse o futuro que hoje se apresenta? Por um lado, é-se obrigado a reconhecer a impossibilidade de dissociar inteiramente a obra do homem, ou seja, o "ressentimento" que Saramago admite ter com relação à Europa, que em muito influenciou suas visões acerca da integração. Vale lembrar, nesse sentido, que o Partido Comunista, ao qual Saramago se filiara em 1969 (GODK, 2016), era contrário à adesão à CEE (PINTO, 2011).

Por outro lado, apesar de se concordar com a existência de uma "identidade cultural profunda" (AGUILERA, 2010, p. 442) entre os povos da península, a defesa de uma rejeição às aproximações com a Europa sugere uma confusão entre os aspectos culturais e os aspectos econômicos e políticos. A cultura, embora importante elemento para harmonização entre os povos, não parece configurar pilar de sustentação suficiente para projetos regionais de integração, como decorre do sonho iberista, ou para se dar as costas a associações mais pragmáticas como a entrada numa comunidade econômica.

O receio de Saramago de ver aniquilada a cultura portuguesa por absorção num quadro maior, este medo de dissolução da cultura portuguesa e o medo da conexão dos países ibéricos à CEE apresentam-se como injustificados ante o profundo sentimento nacional que sempre esteve na base da identidade lusitana. Nas palavras de Eduardo Lourenço, quando está a analisar este enraizamento identitário, "já provamos que não podemos ser digeridos enquanto portugueses" (1994, p. 23).

No que diz respeito a este autor, é auspicioso observar como seu pensamento evoluiu no sentido de atenuar o complexo de inferioridade de sua imagologia. As reflexões que o ensaísta faz posteriormente ao desenvolvimento dos seus conceitos centrais são impressionantes, na medida em que se descobre um Lourenço agora capaz de se questionar se, afinal, aquela Europa objeto de fascínio merecia de fato a admiração irrestrita dos povos de sua periferia: "o drama reside menos no diagnóstico passional ou caricatural da realidade portuguesa ou no catálogo deprimente de carências e reflexos nacionais efetivamente existentes do que na mitificação dessa Europa de fascínio certo e exemplaridade duvidosa" (1994, p. 31).

Avanços econômicos e tecnológicos não significam, necessariamente, avanço cultural. Aliás, a noção de avanço cultural parece implicar naquela noção, perigosa, de superioridade cultural - artifício discursivo muito utilizado na era do imperialismo europeu para justificar a exploração de povos "culturalmente atrasados". Esta construção teórica já foi há muito descartada pela melhor teoria. É sempre bom lembrar, em acréscimo, que esta cultura tão invejada no século XIX foi a responsável pelas barbaridades mais absur- 
das praticadas contra o gênero humano na primeira metade do século XX. Aquela Europa, portanto, não era a "pátria da razão" com a qual sonhavam outros povos (LOURENÇO, 1994).

Uma reflexão paralela a esta decorre de uma constatação que só o desenrolar da história pode produzir, qual seja, a de que, embora índices econômicos sejam importantes para aferir a condição de vida de um povo, não implicam automaticamente uma condição de bem-estar ou de felicidade seja lá o que isto signifique. Lourenço, ao analisar o Portugal contemporâneo, afirma que

\footnotetext{
a história e o destino de Portugal nunca foram trágicos fora da tragédia adiada que a vida é. Também não o são agora. Pela primeira vez, o nosso país vive-se a si mesmo e começa até a ser visto pelos outros, que sabem onde ficamos e quem somos, como um povo insolentemente feliz. Exibicionistamente feliz, até, como nos está nas veras da alma. Antes isso que o masoquismo, um tudo nada hipócrita, com que éramos os "lusíadas coitados". (2018b, p. 71)
}

Não sabemos se o festejado ensaísta português tem razão - novamente nos ataca a desconfiança na precisão de qualquer imagologia. Mas e se isto for o mais importante, ser um povo "feliz", sem a pressão de comparações externas que levam uma nação a se autodepreciar de modo doentio? Seria preciso abandonar o campo da história e ingressar no da memória para compreender, talvez, a alma portuguesa - a do seu povo, entenda-se - e sua relação com o mundo, bem como sua relação com a Europa, e não se fiar de modo excessivo a um sentimento que emerge dos anseios intelectuais de suas elites.

Para finalizar, é preciso lembrar que projetos colonialistas só dão certo por um espaço limitado de tempo. Quando o sentimento nacional surge num determinado território, a colonização torna-se um projeto fadado ao fracasso. A história está aí para prová-lo. Nenhum Estado foi capaz de, ao mesmo tempo, cuidar de si mesmo e de suas colônias com o mesmo grau de empenho, provocando irremediavelmente a revolta e a insubmissão, que terminam por desaguar na independência dos povos colonizados.

Quando Portugal finalmente regressa à casa lusitana, com o fim do Estado Novo e a independência das últimas colônias africanas, este retorno, que sob um ponto de vista limitado pode ser encarado como uma perda, na verdade também pode ser interpretado como uma evolução extremamente positiva. Pela primeira vez, Portugal pode cuidar de si mesmo, com total empenho e sem que lhe pesem as obrigações atreladas ao papel de um Estado colonizador, ainda que isto signifique a perda de benesses imediatas associadas à posse colonial. 
Este retorno de Portugal a si mesmo é também um reencontro com seus vizinhos. Desta vez, não é mais possível virar as costas para a Europa. Embora não seja válida a concepção de que um Estado atingiu o âmago de si mesmo, porque sua realidade é eterno movimento na perenidade, o regresso à casa e ao convívio pacífico e colaborativo com aqueles que sempre estiveram presentes durante o período de sua construção identitária é o mais próximo disto que se pode chegar. Neste sentido limitado, longe de perder-se anonimamente no seio de uma Europa estranha, ao adaptar-se rapidamente a um espaço que, no fundo, sempre lhe fora familiar, Portugal se cumpriu, como desejou, num passado não tão distante, um dos seus maiores poetas.

\section{Referências Bibliográficas}

AGUIAR, João Valente $\mathcal{E}$ BASTOS, Nádia. A História e a construção histórica na obra de José Saramago. Crítica Marxista, Campinas, n. 31, p. 11-22, 2010. Disponível em: <http://bit.ly/2maU0JF>. Acesso em: 10 set. 2019.

AGUILERA, Fernando Gómez (ed.). José Saramago nas suas palavras. Alfragide: Editorial Caminho, 2010.

AMARAL, João Ferreira do. O impacto económico da integração de Portugal na Europa. Nação e defesa, Lisboa, n. 115, p. 113-128, 2006. Disponível em: http:// bit.ly/2k5lq2K. Acesso em: 10 set. 2019.

BOTELHO, Samira Daura. Literatura, história e memória em A jangada de pedra, de José Saramago. Emblemas: Revista do Departamento de História e Ciências Sociais, Catalão, v. 8, n. 2, p. 299-316, 2011. Disponível em: <http://bit.ly/2lGo8fM>. Acesso em: 10 set. 2019.

CABRAL, Francisco Sarsfield. Europa e projecto nacional. Nação e defesa, Lisboa, n. 4, p. 34-43, 1978. Disponível em: <http://bit.ly/2kCQt6o \. Acesso em: 5 abr. 2018.

COELHO, Gislene Teixeira. A jangada de José Saramago e um continente em crise. In: CONGRESSO INTERNACIONAL DA ABRALIC, 13., 2013, Campina Grande. Anais... Campina Grande: Editora Realize, 2013, p. 1-8. Disponível em:<http:// bit.ly/2kpNm1H $\geq$. Acesso em: 22 mar. 2018.

FRAGA, Gustavo de. Antero e o federalismo peninsular. Revista Portuguesa de Filosofia, Ann Arbor, v. 47, n. 2, p. 227-245, 1991.

GODK, Bruna Dancini. Desterritorializações Saramaguianas: uma leitura de A jangada de pedra (José Saramago). Dissertação de mestrado em Letras, Universidade Federal do Paraná, Curitiba, 2016. Disponível em: <http://bit.ly/2m2O3yb $\geq$. Acesso em: 22 mar. 2018.

JUSTO, Carlos Pazos. A jangada de pedra de José Saramago: repertório e sistema interliterário ibérico. Diacrítica: Ciências da Literatura, Braga, v. 22, p. 197-209, 2008. Disponível em: <http://bit.ly/2k97B3l>. Acesso em: 10 set. 2019.

LOURENÇO, Eduardo. Nós e a Europa ou as duas razões. Lisboa: Imprensa Nacional: Casa da Moeda, 1994. 
LOURENÇO, Eduardo. O labirinto da saudade. Lisboa: Gradiva, 2018a.

LOURENÇO, Eduardo. Portugal como destino seguido de Mitologia da saudade. Lisboa: Gradiva, 2018b.

MARQUES, António Henrique Rodrigo de Oliveira. Breve história de Portugal. Lisboa: Editorial Presença, 2009.

MONTEIRO, Nuno Gonçalo \& PINTO, António Costa. A identidade nacional portuguesa. In: PINTO, António Costa (coord.). Portugal contemporâneo. Lisboa: Dom Quixote, 2005, p. 51-65.

NASCIMENTO, Naira Almeida. A jangada e a nau: a nação portuguesa de José Saramago e de Eduardo Lourenço. Revista Letras, Curitiba, n. 90, p. 149-192, 2014. Disponível em: <http://bit.ly/2lHZqLS>. Acesso em: 10 set. 2019.

PEREIRA, João Martins. Pensar Portugal hoje. Lisboa: Dom Quixote, 1971.

PEREIRA, João Martins. No reino dos falsos avestruzes: um olhar sobre a política. Lisboa: A regra do jogo, 1983.

PEREIRA, Maria de Lourdes. Em busca de uma memória ibérica. Res-publica: Revista Lusófona de Ciência Política e Relações Internacionais, v. 5, n. 6, p. 7-15, 2007. Disponível em: <http://bit.ly/2maVMKP>. Acesso em: 10 set. 2019.

PINTO, António Costa $\mathcal{E}$ TEIXEIRA, Nuno Severiano. Portugal e a integração europeia, 1945-1986. In: PINTO, António Costa E TEIXEIRA, Nuno Severiano (org.). A Europa do Sul e a construção da União Europeia: 1945-2000. Lisboa: Imprensa de Ciências Sociais, 2005, p. 17-43.

PINTO, Fernanda Maria Reis da Fonseca Ferreira. A integração de Portugal nas Comunidades Europeias. Dissertação de mestrado em Estudos Europeus, Universidade de Coimbra, Coimbra, 2011. Disponível em: <http://bit.ly/2m2OSaf $>$. Acesso em: 5 abr. 2018.

QUENTAL, Antero de. Causas da decadência dos povos peninsulares. Lisboa: Tinta da China, 2017.

ROCAMORA, Jose Antonio. Causas do surgimento e do fracasso do nacionalismo ibérico. Análise Social, v. 28, n. 122, p. 631-652, 1993. Disponível em:<http://bit. ly/2k7MtKQ>. Acesso em: 10 set. 2019.

SARAMAGO, José. A jangada de pedra. Porto: Porto Editora, 2015.

SILVA, Marisa Corrêa. José Saramago: o iberismo como utopia. Acta Scientiarum, Maringá, v. 24, n. 1, p. 67-70, 2002.

SOBRAL, José Manuel. Portugal, portugueses: uma identidade nacional. Lisboa: Fundação Francisco Manuel dos Santos, 2012.

Recebido: 14/08/2018 - Aprovado: 04/04/2019

Editores responsáveis pela publicação:

Júlio Pimentel Pinto e Flavio de Campos 